\title{
A Study of Some Motile Group D Streptococci
}

\author{
By BARBARA M. LUND \\ Agricultural Research Council, Food Research Institute, \\ Low Temperature Research Station, Downing Street, Cambridge*
}

(Accepted for publication Io April 1967)

\begin{abstract}
SUMMARY
Thirteen strains of motile enterococci showed more similarity, in their physiological reactions, to Streptococcus faecium than to $S$. faecalis. A serological study of the type antigens divided the motile strains into four sets; (1) three strains previously described as $S$. faecium serotype 29 , (2) one strain reacting as $S$. faecium serotype 38 , (3) five strains showing a specific reaction with antiserum prepared to one of them ('serotype $4725^{\prime}$ '), (4) four untyped strains. Esterase and protein patterns from the soluble fractions of the motile strains were examined by electrophoresis in polyacrylamide gel and were different from those of non-motile strains of $S$. faecalis, $S$. faecium and $S$. durans. Extracts of the three motile strains of $S$. faecium type 29 showed a common esterase pattern, extracts from five strains of serotype 4725 showed three different esterase patterns. The motile strain of $S$. faecium serotype 38 gave extracts with a strong esterase band which differed from the very weak bands shown by extracts of non-motile strains. Differences in esterase pattern could be found between motile strains whether untyped, of different serotypes, or of the same serotype. Comparison of the 'protein patterns' of motile strains gave some indication that major protein bands occurred at similar positions after electrophoresis.
\end{abstract}

\section{INTRODUCTION}

A previous study by gel electrophoresis of soluble cell components (Lund, 1965) showed that 12 strains of Streptococcus faecalis and its varieties 'zymogenes' and 'liquefaciens' of eight serotypes had a similar pattern of separated protein bands, and showed strong bands with esterase activity. Strains of $S$. faecium of I9 serotypes gave 'protein patterns' with major bands having similar mobility (amongst these strains) but strong esterase bands were not detected. The pattern of protein bands of $S$. faecium and $S$. durans differed from that of $S$. faecalis. Of 2 I strains of $S$. faecium and $S$. durans examined initially, one strain had a distinctive pattern of proteins and strong bands of esterase activity; this strain was the only motile one among those initially studied.

The purpose of the present work was to study, by gel electrophoresis, extracts of other motile strains of enterococci from diverse sources to compare their protein components and esterase enzymes, and to correlate this comparison with a study of some physiological and serological properties. Physiological properties and agglutination reactions of a large number of strains of motile enterococci have previously been studied by Graudal (1952, 1955, I957 $a, b)$.

\footnotetext{
* Present address: Agricultural Research Council, Food Research Institute, Earlham Laboratory, Recreation Road, Norwich.
} 


\section{METHODS}

Organisms. The motile enterococci studied are listed in Table I. They were compared with strains of Streptococcus faecalis and $S$. faecium which have previously been described (Lund, 1965). Cultures of $S$. faecalis and $S$. faecium were stored on slopes of Hartley's digest agar at $5^{\circ}$. Because cultures of motile organisms tended to die during storage they were maintained as stab cultures in Brain Heart Infusion agar Difco) at $5^{\circ}$ and were subcultured at intervals of 1 month.

\section{Table I. Strains of motile group D streptococci studied}

Strain (species name is that used in the reference cited)

S. faecium (type 29, P $14 / 6$ type strain)

S. faecium

S. faecium

S. faecalis

Streptococcus sp.
Streptococcus sp.

Streptococcus sp.

Streptococcus sp.

Streptococcus sp.

Streptococcus sp. ATCC 12818

Streptococcus sp. ATCC 12819

Streptococcus sp. ATCC 13638

S. faecalis

ATCC 12755

NCTC 4725

D I003(b)

"pigmented" strain)

D I006(c)

D IOIO(c)

ATCC 12817
Source

Pig colon

Human faeces

Piglet

Probably human

$\mathrm{D} 1000(\mathrm{~b})$

(described as 'pigmented'

Oropharynx, patient undergoing

treatment for pernicious anaemia

Mouth, patient with untreated oral cancer

As ATCC 12817

Spinal fluid, patient with chronic

meningitis

Milk
Reference

Sharpe \& Fewins

(1960); Barnes (1964)

Pownall (1935)

Graudal (1957 $a, b)$

collection, isolated mainly from

human faeces

Motility was demonstrated by stab inoculation of the organism into Brain Heart Infusion Broth (Difco) $+0.25 \%$ (w/v) Bacto-Agar (Difco) and incubation at $25^{\circ}, 30^{\circ}$ or $37^{\circ}$ for $24 \mathrm{hr}$. The diffuse growth of motile strains could be distinguished from the more discrete growth of non-motile strains. Motility was confirmed by microscopical examination of living cells. Flagella were stained by Leifson's technique (Leifson, 195I).

Biochemical tests. The methods used for testing haemolysis, growth in presence of $40 \%$ bile, sensitivity to potassium tellurite, growth at $10^{\circ}$, growth at $45^{\circ}$, growth in presence of $6.5 \% \mathrm{NaCl}$, survival at $60^{\circ}$ for $30 \mathrm{~min}$. were those described by Barnes, Ingram \& Ingram (1956). The appearance of colonies on thallous acetate-tetrazolium agar (TITg) was studied using thallous acetate agar (Baltimore Biological Laboratory) and the method described by Barnes (1956). In all the above tests incubation was at $37^{\circ}$ unless otherwise specified. Production of acid in carbohydrate media was studied by the method of Whittenbury (1963) utilizing a soft agar medium. The basal medium contained meat extract (Lab-Lemco), $5 \mathrm{~g}$.; peptone (Evans), $5 \mathrm{~g}$.; yeast extract (Difco), $5 \mathrm{~g}$.; Tween $80,0.5 \mathrm{ml}$.; agar (Davis), I.5 g., distilled water to I 1 . As $\mathrm{pH}$ indicator 
$5.6 \mathrm{ml}$. of a $\mathrm{I} \cdot 6 \%(\mathrm{w} / \mathrm{v})$ solution of bromocresol purple in ethanol was added to $\mathrm{I} l$. of medium and the $\mathrm{pH}$ adjusted to 6:8-7.0. Carbohydrate substrates (B.D.H. Laboratory reagent grade), as $5 \%(\mathrm{w} / \mathrm{v})$ solutions in distilled water, were sterilized separately at $120^{\circ}$ for $15 \mathrm{~min}$. and added to the basal medium to give a final concentration of $0.5 \%(\mathrm{w} / \mathrm{v})$. The melted medium was cooled to $45^{\circ}$ before inoculating and then allowed to set. Results were recorded after incubation at $37^{\circ}$ for 3 days. Tests for utilization of individual carbohydrates as sources of energy for growth were made by the technique of Deibel, Lake \& Niven (1963). For aerobic tests $10 \mathrm{ml}$. quantities of media in T-tubes were inoculated and shaken at I04 strokes/min. with an amplitude of $2.25 \mathrm{in}$. on a reciprocal shaker; for anaerobic tests tubes containing $10 \mathrm{ml}$. of inoculated media were placed in a desiccator under an atmosphere of $95 \%$ nitrogen + $5 \%$ carbon dioxide. After incubation for $\mathrm{I} 8 \mathrm{hr}$ at $30^{\circ}$ growth was estimated by turbidity measured in an 'EEL' nephelometer (Evans Electroselenium Ltd., Harlow, Essex). A positive result was taken as a turbidity, in the presence of added carbohydrate, equal to at least twice that in the basal medium.

Serological test for group $D$ antigen. Extracts prepared as for polyacrylamide gel electrophoresis were tested for precipitin reaction with group D Streptococcus Grouping Serum (Burroughs Wellcome and Co.). Results were recorded $30 \mathrm{~min}$. after testing.

Serological typing. The methods used were based on those described by Sharpe $\&$ Shattock (1952).

Type antisera. In preliminary experiments, extracts of motile strains were tested against Streptococcus faecium type antisera which had been prepared by Dr M. E. Sharpe, National Institute for Research in Dairying, Shinfield, Reading. In subsequent experiments antisera were prepared to motile strains P I 4/6, ATCC 13638, NCTC 4725 and the non-motile strain P $17 / 8$, using the following technique. Cultures were grown in $80 \mathrm{ml}$. of medium containing glucose, I g.; peptone(Evans), I g.; Lab-Lemco (Oxoid), I g.; $\mathrm{NaCl}, 0.5 \mathrm{~g}$.; distilled water to $100 \mathrm{ml}$. pH 7.0-7.2 (medium A). After incubation at $37^{\circ}$ for $18 \mathrm{hr}$ cells were separated by centrifugation, washed twice in $50 \mathrm{ml}$. of $0.85 \%(\mathrm{w} / \mathrm{v}) \mathrm{NaCl}$ in water and resuspended in $20 \mathrm{ml}$. solution containing $0.85 \%$ $(\mathrm{w} / \mathrm{v}) \mathrm{NaCl}$ and $0 . \mathrm{I} \%(\mathrm{w} / \mathrm{v}) \mathrm{HCHO}$. The suspension was kept at room temperature for $24 \mathrm{hr}$, after which tests for viable organisms were negative. The suspension was adjusted to an opacity of 7-8 using standard opacity tubes (Burroughs Wellcome and Co.) and stored at $-20^{\circ}$.

Two rabbits were inoculated by intravenous injections with each organism. An initial sensitizing dose of $0.4 \mathrm{ml}$. was given, and after 5 days the following series of injections was started: three injections of $0.4 \mathrm{ml}$. (week $\mathrm{I}$ ), three of $0.8 \mathrm{ml}$. (week 2), three of $\mathrm{I} \cdot 0 \mathrm{ml}$. (week 3). Three days after the last injection a test bleeding showed satisfactory antibody production; $25 \mathrm{ml}$. of blood was withdrawn from each rabbit. After clot formation the separated serum was stored at $-20^{\circ}$ without preservative.

Absorbed antisera. For the initial experiments the absorbed type antisera to a range of serotypes of Streptococcus faecium had been prepared by Dr M. E. Sharpe. Further absorbed antisera were prepared by the following technique. The organism used for the absorption was grown in $200 \mathrm{ml}$. medium $\mathrm{A}$ at $30^{\circ}$ for $18 \mathrm{hr}$, the cells harvested by centrifuging, washed and resuspended in $\mathrm{I} 0 \mathrm{ml} .0 .85 \%(\mathrm{w} / \mathrm{v}) \mathrm{NaCl}+0 . \mathrm{I} \%(\mathrm{w} / \mathrm{v})$ HCHO. The suspensions were then heated at $70^{\circ}$ for $30 \mathrm{~min}$. and washed on the centrifuge in saline-formaldehyde solution. The packed cells were resuspended in four 
times their volume of antiserum and incubated at $37^{\circ}$ for $2 \mathrm{hr}$, stirring frequently. After storage at $+1^{\circ}$ overnight the cells were sedimented by centrifugation, the antiserum removed and tested against an extract of the homologous organism.

Extraction of type antigens. Cultures in $20 \mathrm{ml}$. of medium A were incubated at $25^{\circ}$ for $24 \mathrm{hr}$. Hydrochloric acid extracts were prepared by a technique based on Lancefield's (I933) method. The sediment from $20 \mathrm{ml}$. of growth medium was resuspended in $0.5 \mathrm{ml}$. of $\mathrm{HCl}(0.05 \mathrm{~N}$ or $0.0 \mathrm{IN})$ in $0.85 \%(\mathrm{w} / \mathrm{v}) \mathrm{NaCl}$, heated in a boiling-water bath for $10 \mathrm{~min}$., cooled, centrifuged and the clear supernantant neutralized by the addition of I N- or $0.2 \mathrm{~N}-\mathrm{NaOH}$ to an end-point with phenol red; I drop of $\mathrm{I} \%(\mathrm{w} / \mathrm{v})$ solution of Thiomersal (British Drug Houses Ltd.) was added as preservative.

Removal of flagella before extraction of type antigens. Cultures in $20 \mathrm{ml}$. of medium A were incubated at $25^{\circ}$ for $24 \mathrm{hr}$, cells were separated by centrifuging at $1000 \mathrm{~g}$ for $20 \mathrm{~min}$. and resuspended in $0.85 \%(\mathrm{w} / \mathrm{v})$ saline. A sample stained by Leifson's (195I) technique showed the presence of flagella, many of which had become detached. In order to detach remaining flagella $10 \mathrm{ml}$. of the bacterial suspension was treated in a homogenizer (Measuring and Scientific Equipment Ltd.) using a blending speed of approximately $12,000 \mathrm{rev} . / \mathrm{min}$. for $2 \mathrm{~min}$. After centrifuging at $10,000 \mathrm{~g}$ for $15 \mathrm{~min}$. detached flagella tended to remain in the supernatant, the sedimented cells were resuspended in $10 \mathrm{ml}$. of fresh $0.85 \%(\mathrm{w} / \mathrm{v})$ saline. This centrifuging and resuspension in fresh saline was repeated 4 times, giving a final sediment which consisted mainly of intact, deflagellated organisms. A hydrochloric acid extract was prepared as previously described, using for comparison a cell sediment prepared without removal of flagella.

Precipitin tests. Strong precipitin reactions were observed by the capillary tube technique of Swift, Wilson \& Lancefield (1943). For weaker reactions it was necessary to use the precipitin ring technique (Sharpe \& Shattock, 1952). In each case extracts prepared with $0.05 \mathrm{~N}-\mathrm{HCl}$ in $0.85 \%(\mathrm{w} / \mathrm{v}) \mathrm{NaCl}(\mathrm{pH} \mathrm{I} \cdot 6)$ gave a stronger precipitin reaction than those prepared with $0.0 \mathrm{I} \mathrm{N}-\mathrm{HCl}$ in $0.85 \%(\mathrm{w} / \mathrm{v}) \mathrm{NaCl}(\mathrm{pH} 2 \cdot \mathrm{I})$; this differed from the results obtained by Maxted \& Fraser (I966) with Streptococcus faecalis strains.

Gel diffusion tests. These were made on microscope slides 3 in. $\times \mathrm{I}$ in. covered with $2 \mathrm{ml}$. of the following medium: barbitone-acetate buffer (Oxoid), $8 \cdot 25 \mathrm{~g}$., thiomersal (B.D.H.), $0 . \mathrm{I}$ g., Ionagar no. 2 (Oxoid), $10 \mathrm{~g}$., distilled water to I 1 . Wells were cut in the agar, filled with antiserum or antigen extract and the slides placed at $0-5^{\circ}$ for $24 \mathrm{hr}$ in a moist atmosphere for precipitin lines to develop.

Immuno-electrophoresis. Lantern cover glasses $3 \frac{1}{4}$ in. $\times 3 \frac{1}{4}$ in. were covered with $\mathrm{I} 2 \mathrm{ml}$. of the medium described for gel diffusion tests. Wells were cut and filled with antigen extract. For electrophoresis the tank buffer contained barbitone-acetate buffer (Oxoid) $8.25 \mathrm{~g}$.; distilled water to 21 .; a potential difference of $8-10 \mathrm{~V}$. per $\mathrm{cm}$. was applied for $1.5 \mathrm{hr}$. Trenches were made, filled with antiserum, and the preparation was placed at $0-5^{\circ}$ in a moist atmosphere for $24 \mathrm{hr}$ to allow development of precipitin lines.

Effect of periodate on type antigens. Attempts were made to detect sensitivity of the antigens to periodate, using a method similar to that of Sharpe (1964). Neutralized hydrochloric acid extract $0.5 \mathrm{ml}$., or the acetone-precipitated fraction of this extract, was treated with an equal volume of $0.4 \mathrm{M}$-acetate buffer $\mathrm{pH}_{4}$ containing $0.08 \mathrm{M}$ sodium periodate. After incubation at $37^{\circ}$ for $16 \mathrm{hr} 0.05 \mathrm{ml}$. of $5 \%(\mathrm{v} / \mathrm{v})$ ethylene glycol was added to destroy the periodate, the $\mathrm{pH}$ was adjusted to 7 with $\mathrm{N}-\mathrm{NaOH}$ 
and the extract was tested against the homologous antiserum. Controls were included in which antigen extract was replaced by water.

Effect of trypsin on type antigens. Crystalline trypsin was added to the neutralized hydrochloric acid extract to give a concentration of $2 \mathrm{mg} . / \mathrm{ml}$. After incubation at $37^{\circ}$ for $3 \mathrm{hr}$ the extract was tested against the homologous antiserum.

Preparation of cell extracts for electrophoresis. Cultures were grown in $800 \mathrm{ml}$. volumes of Brain Heart Infusion Broth (Difco Laboratories) in static culture for $16 \mathrm{hr}$ at $30^{\circ}$. The bacteria were harvested by centrifugation, washed, and the wet pellet of cells resuspended in half its weight of tris-citrate buffer $\mathrm{pH} 8 \cdot 7$ (see below). The suspension was frozen at $-20^{\circ}$, disrupted in an X-press (AB Biox, Box 235, Nacka 2, Sweden), melted and clarified by centrifugation as previously described (Lund, 1965). The final extracts, with a protein content of $30-50 \mathrm{mg} . / \mathrm{ml}$., as estimated by the method of Lowry, Rosebrough, Farr \& Randall (195I) were stored at $-20^{\circ}$.

Electrophoresis in polyacrylamide gel. Conditions for electrophoresis, staining for protein and for esterase enzymes (hydrolysing $\alpha$-naphthyl acetate) and for photography were as previously described (Lund, 1965). The gel was prepared in buffer containing tris, $38 \mathrm{mM}$, citric acid $2.5, \mathrm{mM}\left(\mathrm{pH} 8.7\right.$ at $\left.25^{\circ}\right)$; the buffer for electrode vessels contained boric acid, $7.22 \mathrm{~g} . / 1$., borax, $15.75 \mathrm{~g} . / 1 .\left(0.28 \mathrm{M}\right.$ in terms of borate) $\mathrm{pH} 8.8$ at $25^{\circ}$.

\section{RESULTS}

\section{Biochemical properties of motile strains}

Table 2 summarizes the properties of motile strains of enterococci and includes a comparison of the motile and non-motile strains in serotype 38 .

The term 'enterococci' [introduced by Sherman (1937) to include streptococci giving positive results in the 'Sherman tests' (Deibel, 1964)], excludes Streptococcus bovis and $S$. equinus. In general the motile strains gave positive results in the Sherman tests except for I strain, ATCC I 2755 which failed to grow at $45^{\circ}$. The nature of haemolysis, growth in presence of $0.04 \%(\mathrm{w} / \mathrm{v})$ potassium tellurite, production of acid from sorbitol and $\mathrm{L}(+)$-arabinose, and appearance of colonies on thallous acetate-tetrazolium agar are well-established tests used to differentiate $S$. faecalis from $S$. faecium and $S$. durans (Deibel, 1964). Sensitivity of the motile strains to potassium tellurite was intermediate between that of $S$. faecalis and that of $S$. faecium and $S$. durans, in agreement with the observation of Graudal (I957b). Like $S$. faecium, motile strains grew well in the presence of $\mathrm{L}(+)$-arabinose, and marked acid production occurred in $24 \mathrm{hr}$. In contrast with $S$. faecium, many of the motile strains showed some production of acid in the presence of sorbitol, but generally the change in colour of the indicator was slower and less well-marked than in the case of $S$. faecalis. Strain NCTC 4725 was received as a strain of $S$. faecalis. It differed from typical $S$. faecalis in (i) appearance on thallous acetate-tetrazolium agar, (ii) fermentation of $L(+)$-arabinose and not of sorbitol, (iii) failure to utilize citrate or glycerol + fumarate as energy sources. The results in Table 2 show that this strain differed in several respects from typical $S$. faecalis and in common with other motile strains showed more similarity to $S$. faecium than to $S$. faecalis in these tests. 


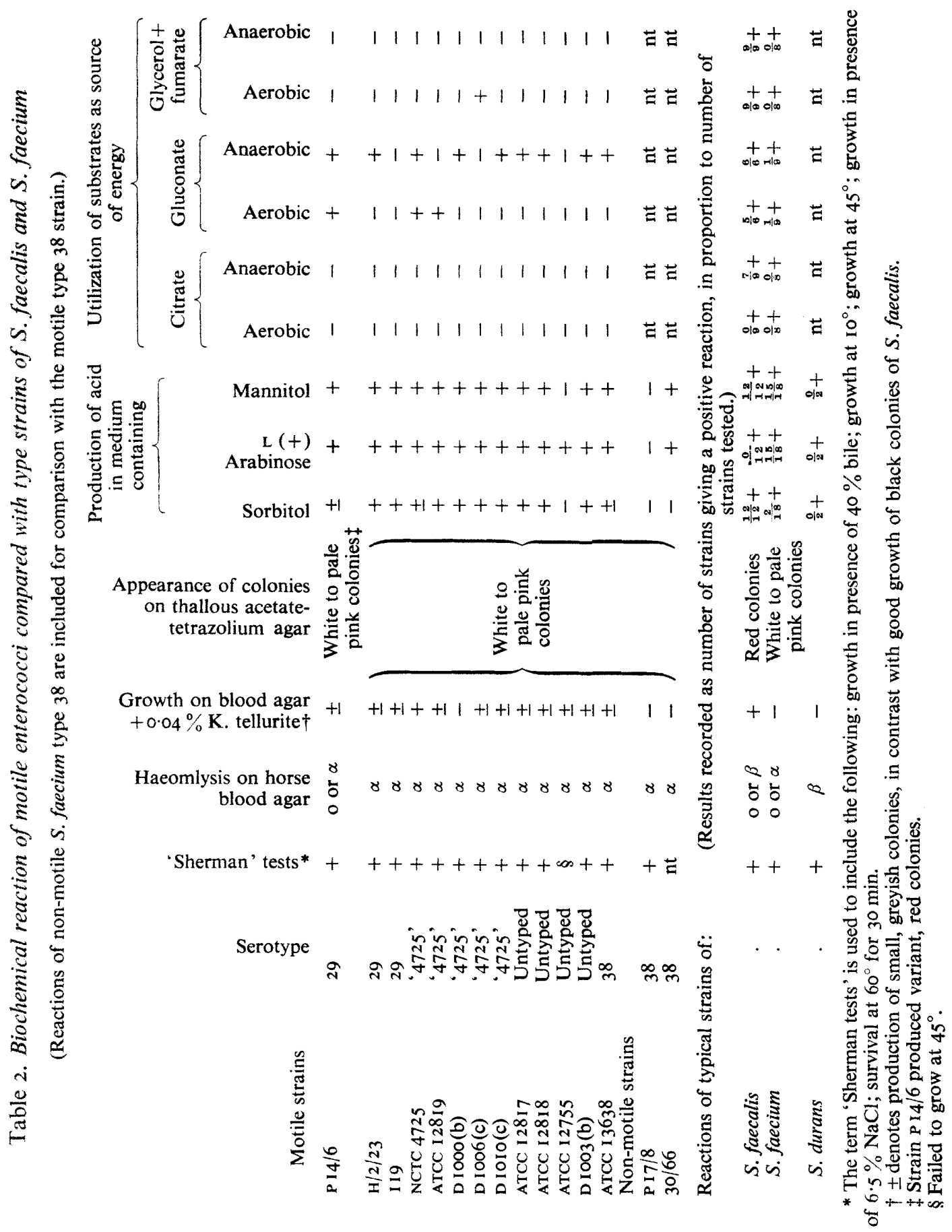




\section{Serological typing}

Of the 13 motile strains, three belonged to Streptococcus faecium serotype 29 of which one, P I $4 / 6$, is the type strain. Extracts of the remaining Io strains were tested against antisera which were available to 17 serological types of $S$. faecium; only one strain gave a reaction, ATCC 13638 , which belonged to serotype 38 (type strain nonmotile $\left.P_{17} / 8\right)$. To confirm these results antisera were prepared to type strain P $14 / 6$ (type 29 , motile), type strain P I $7 / 8$ (type 38 , non-motile), ATCC 13638 and also to the untyped strain, NCTC 4725 . Precipitin reactions with these antisera are shown in Table 3.

Table 3. Precipitin reactions of extracts of motile enterococci and of a non-motile type 38 strain of $S$. faecium

\begin{tabular}{|c|c|c|c|c|}
\hline & \multicolumn{4}{|c|}{ Antiserum to } \\
\hline & $\begin{array}{l}\text { P 14/6 } \\
\text { S. faecium } \\
\text { type } 29, \\
\text { type strain }\end{array}$ & $\begin{array}{l}\mathrm{P} \text { I } 7 / 8 \text { (non-motile) } \\
S \text {. faecium } \\
\text { type } 38 \\
\text { type strain }\end{array}$ & ATCC 13638 & NCTC 4725 \\
\hline $\begin{array}{l}0.05 \mathrm{~N}-\mathrm{HCl} \text { saline } \\
\text { extract of - }\end{array}$ & & & & \\
\hline $\mathrm{P} 14 / 6$ & + & - & - & + \\
\hline $\mathrm{H} / 2 / 23$ & + & - & - & + \\
\hline 119 & + & - & - & + \\
\hline PI $7 / 8$ (non-motile) & - & + & + & - \\
\hline ATCC 13638 & - & + & + & - \\
\hline NCTC 4725 & - & - & - & + \\
\hline ATCC 12819 & - & - & - & + \\
\hline D $1000(b)$ & - & - & - & + \\
\hline D $1006(c)$ & - & - & - & + \\
\hline DIOIO(c) & - & - & - & + \\
\hline ATCC 12817 & - & - & - & - \\
\hline $\operatorname{ATCC} 12818$ & - & - & - & - \\
\hline ATCC 12755 & - & - & - & - \\
\hline$D 1003(b)$ & - & - & - & - \\
\hline
\end{tabular}

In each case absorption of the antiserum with a heterologous reacting organism abolished the precipitin reaction with the homologous organism. Gel diffusion tests showed reactions of identity between precipitin lines of homologous and heterologous extracts reacting with antiserum to NCTC 4725 . The term 'type 4725 ' will be used to describe organisms reacting with antiserum to NCTC 4725 , but not with antiserum to $\mathrm{P} 14 / 6$.

The extracts reacting with antiserum to NCTC 4725 included those of the Streptococcus faecium type 29 strains PI4/6, H/2/23 and II9. Antiserum to PI4/6, which produced a strong precipitin reaction with the homologous extract, gave no reaction with an extract of NCTC 4725 (Table 3). The precipitin line produced by extract of P I $4 / 6$ and antiserum to NCTC 4725 did not give a reaction of identity with the line produced by PI $4 / 6$ and the homologous antiserum (Fig. I). This indicates that two antigenic groups were present in acid extracts of strain P I $4 / 6$, one of which reacted with antiserum to NCTC 4725 but failed to induce detectable antibody formation. The two antigens could be distinguished by immuno-electrophoresis of an acid extract of strain P I $4 / 6$. The antigen revealed by the homologous antiserum showed a lower 
mobility than that revealed by antiserum to NCTC 4725 (Fig. 2). Immuno-electrophoresis of extracts of 'type 4725 ' strains revealed a single precipitin with a similar mobility in each extract under these conditions.

Gel diffusion tests showed that the precipitin line produced by Streptococcus faecium type 38 strain $P_{17} / 8$, and by ATCC 13638 against antiserum to either of these strains gave a reaction of identity; by immuno-electrophoresis a single antigen with the same mobility was detected in extracts of each strain.

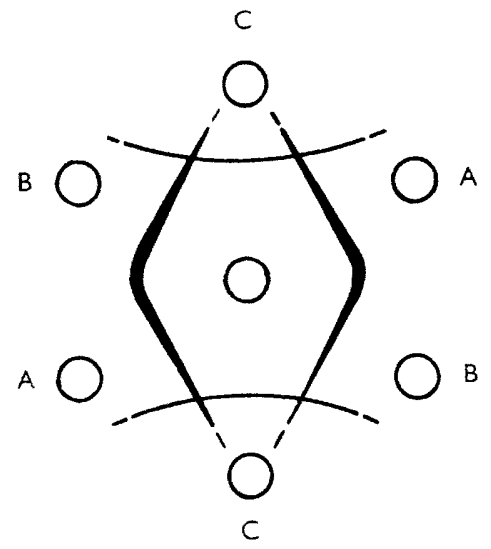

Fig. 1

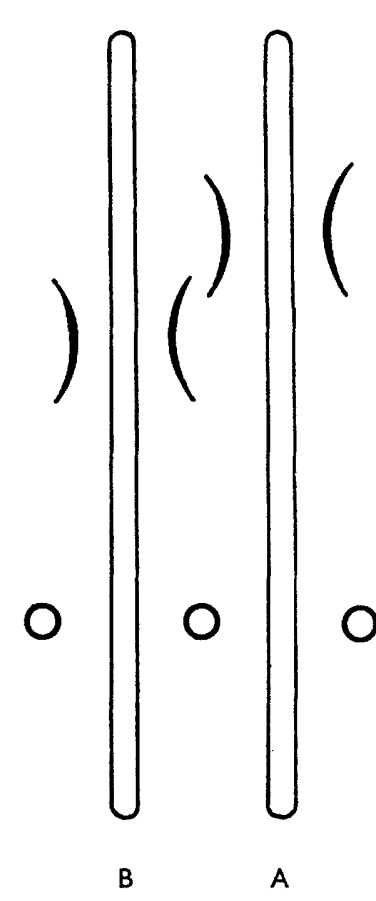

Fig. 2

Fig. I. Diagram of gel diffusion test of extract of strain P 14/6 (S. faecium type 29, type strain, motile) against homologous antisera and against antiserum to strain NCTC 4725. Centre well contained $0.05 \mathrm{~N}-\mathrm{HCl}$ extract of strain P I $4 / 6$. Outer wells A and B contained antisera, from two different rabbits, to strain P 14/6; C contained antiserum to strain NCTC 4725 .

Fig. 2. Diagram of immuno-electrophoresis of extract of strain PI4/6. An $0.05 \mathrm{~N}-\mathrm{HCl}$ extract of strain PI4/6 was placed in the three wells. After electrophoresis trench A was filled with antiserum to strain NCTC 4725 , trench B was filled with antiserum to strain P $14 / 6$.

The nature of the type antigens studied. The experiments relating to the chemical nature of the antigens were inconclusive. Treatment with $0.08 \mathrm{M}$-sodium periodate for $16 \mathrm{hr}$ at $30^{\circ}$ failed to destroy the antigens, although precipitin reactions of periodatetreated extracts tended to be weaker than those of control extracts. Treatment with $2 \mathrm{mg}$. $/ \mathrm{ml}$. of trypsin for $3 \mathrm{hr}$ at $37^{\circ}$ failed to inhibit precipitin reactions.

The immunization procedure for serological typing of enterococci involves the use of formalin-killed suspensions. In the case of motile organisms this procedure may involve production of antibodies to flagella. During the production of acid extracts by the Lancefield method it is not known whether the serological reaction of the flagellar protein would be destroyed. The failure of trypsin to abolish the precipitin 
reaction was inconclusive, since the flagellar protein of Salmonella typhimurium has been reported to be insensitive to trypsin and to other proteolytic enzymes (Stocker \& Campbell, 1959). Cultures of strain P I 4/6 (type 29) and of strain NCTC 4725 were harvested and the flagella removed before preparation of acid extracts for typing. The resulting extract of P14/6 and a control extract of untreated organisms gave equally strong precipitin reactions with homologous antisera and with antiserum to NCTC 4725 ; in the case of strain NCTC 4725 , an extract prepared after removal of flagella and a control extract also gave equally strong precipitin reactions. It is concluded that the antigens studied in acid extracts of these motile streptococci were not derived from the flagella.

\section{Electrophoresis of soluble components of disrupted organisms}

\section{(i) Esterases}

Preliminary experiments (Lund, 1965) showed the presence of esterase bands in extracts of motile strain P I $4 / 6$. The relative intensity of these bands was affected by the presence of buffer during cell disruption. In experiments described below organisms were suspended in tris-citrate buffer before disruption.

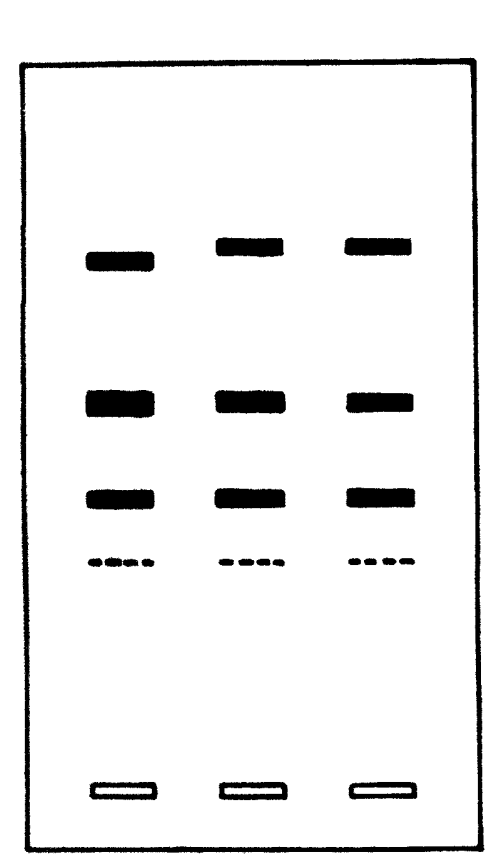

(a) (b)

Fig. 3

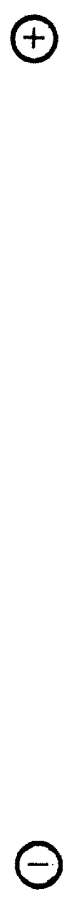

(c)

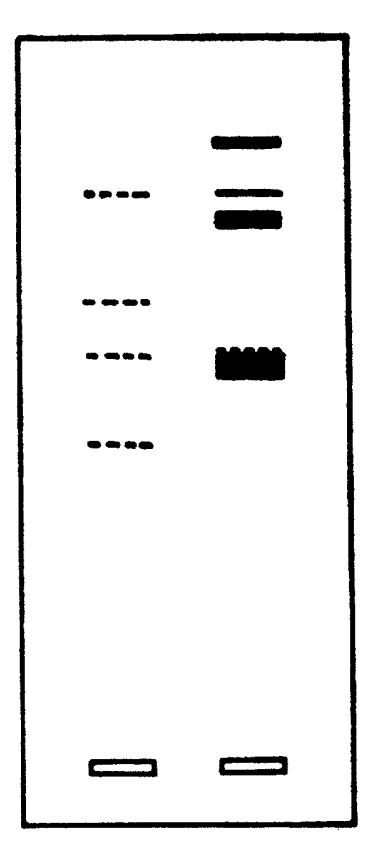

(a)

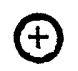

(b)

Fig. 4

Fig. 3. Diagram of esterases of motile, type 29 strains of $S$. faecium separated by electrophoresis on polyacrylamide gel. $(a)=$ strain P14/6 (S. faecium, type 29, type strain); (b) $=$ strain $\mathrm{H} / 2 / 23 ;(c)=$ strain 119 .

Fig. 4. Diagram of esterases of a non-motile (type 38 ) strain of $S$. faecium and a motile (type 38 ) strain of streptococcus, studied by electrophoresis on polyacrylamide gel. $(a)=$ strain $17 / 8$ (non-motile); $(b)=$ strain ATCC 13638 (motile). 
Type 29 strains. P I4/6, H/2/23, I19, all motile, showed similar esterase patterns (Fig. 3).

Type 38 strains. Esterase bands of the motile strain ATCC 13638 , and non-motile type 38 strain P $17 / 8$ (type strain), are illustrated in Fig. 4. The motile strain showed strong esterase bands, the non-motile strain showed weak bands with esterase activity and with different mobilities from those of the motile strain.

'Type 4725 ' strains. Esterase patterns are shown in Figs 5 and 6, inserts $(e)$ to $(j)$. Strains reacting with antiserum to NCTC 4725 gave a range of different esterase patterns, only strain D Ioro $(c)$ gave a pattern identical to that of NCTC 4725 .

Untyped strains gave esterase patterns shown in Fig. 5 and Pl. I, fig. I, inserts $(a)$ to $(d)$. Strains D $1003(b)$ and ATCC 12755 gave esterase bands at similar positions.

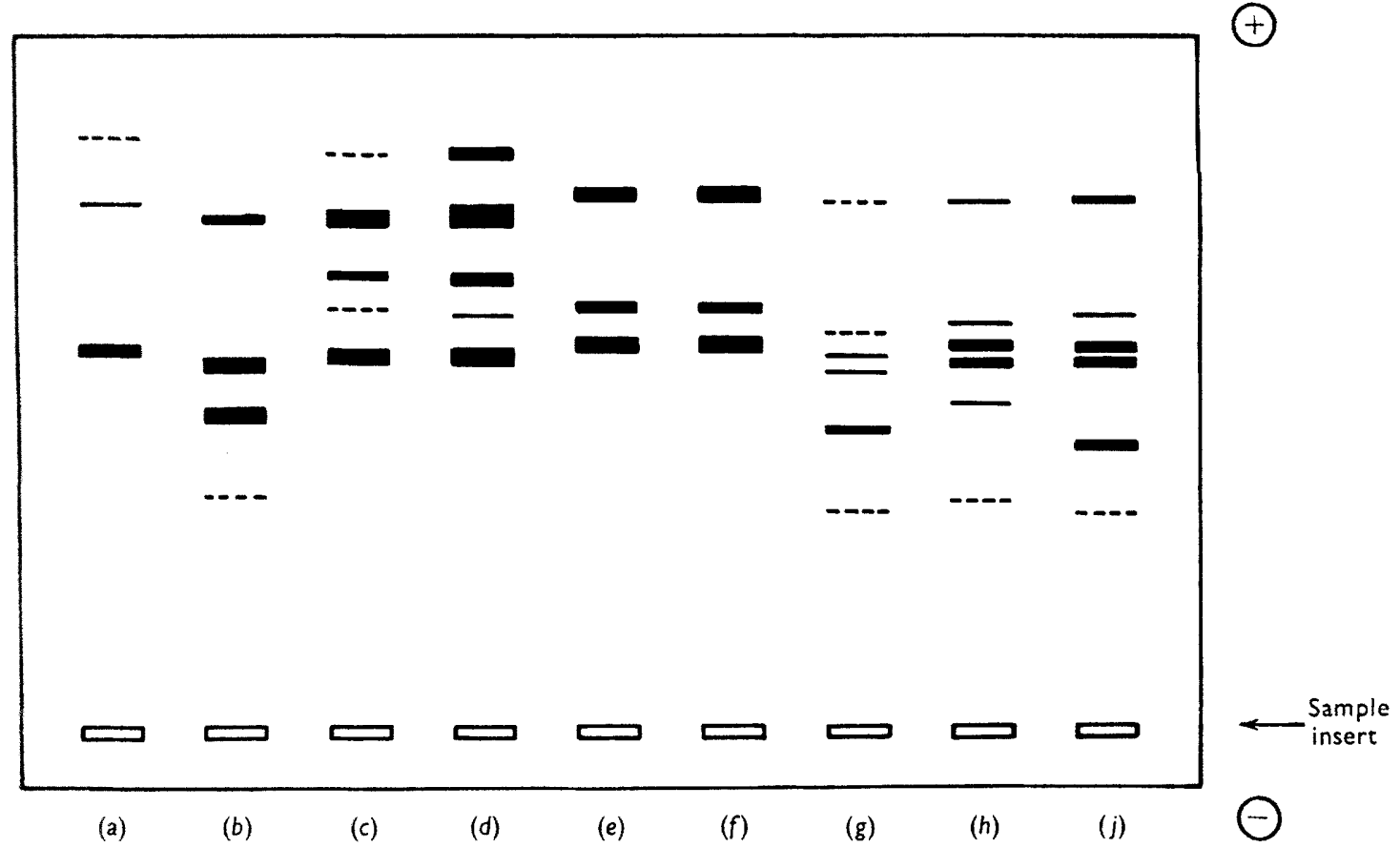

Fig. 5. Diagram of esterases of a range of motile group D streptococci, studied by electrophoresis on polyacrylamide gel. Inserts $(a)-(d)$ contained extracts of untyped strains; inserts $(e)-(j)$ contained extracts of strains reacting with antiserum to NCTC 4725 .
(a) = strain ATCC 12817 ;
(c) = strain D 1003 (b);
(b) = strain ATCC 1 28I8;
$(e)=$ strain NCTC 4725 ;
$(g)=$ strain ATCC I 2819;
$(j)=$ strain D $1006(c)$.
$(d)=$ strain ATCC 12755 ;
$(f)=$ strain D $1010(\mathrm{c})$;
$(h)=$ strain D $1000(b)$;

(ii) Protein bands

Initial experiments showed that the pattern of protein bands from a motile strain (P I4/ ) differed from that of other strains of Streptococcus faecalis and S. faecium (Lund, 1965). The major differences were most clearly seen in the case of bands with $\bar{E}_{f}$ values (Fowler, Coble, Cranmer \& Brown, I963) between 25 and 60 (approx.), the region indicated by the bracket in Pl. I, fig. 2. No difference was found between the protein patterns of extracts prepared in water and those prepared in tris-citrate buffer. 
Protein patterns of other motile strains are shown in P1. I, fig. 2. In general the motile strains resembled the original strain (P I4/6) in showing five clear bands with $\bar{E}_{f}$ values between 25 and 60 . In one case (strain ATCC 12755 ) the forward band was relatively weak, in other cases there were slight differences in the position of these bands and some strains showed a sixth band in this region.

Type 38 strains. There was a clear difference between the protein patterns of motile and non-motile strains within this serotype; strain ATCC 13638 gave a pattern similar to that of the remaining motile strains, P I $7 / 8$ gave a pattern resembling that of other non-motile strains of Streptococcus faecium (Lund, 1965).

The effect of presence of flagella. It did not seem likely that subunits of flagellar protein contributed to the protein pattern since flagella tended to be broken off and separated from the cells during harvesting and washing. Deliberate removal of flagella, by a method similar to that described in the section on serological methods, before preparation of extracts of strain P I 4/6 in the X-press, had no observable effect on the protein pattern obtained.

\section{DISCUSSION}

Although streptococci are generally considered to be non-motile, many workers have studied motile strains belonging to group $D$, isolated from a wide variety of sources (e.g. Pownall, 1935; Auerbach \& Felsenfeld, 1948; Ødegaard \& Gardborg, 1953; Liu, Lindberg \& Mason, 1955; Hugh, 1959; Langston, Guttierez \& Bouma, 1960; Courtieu, Le Tellier, Guillermet, Imbert \& Longeray, I964; de Saint Aubert, Dubouclard, Roumiantzeff \& Vaugon, I964). Cowan \& Steel (I965) stated 'we confirmed Pownall's (I935) observation that many group D streptococci are motile'. The most extensive studies of motile enterococci appear to have been made by Graudal [1952, 1955, 1957a, $b$, Graudal \& Birch-Anderson, 1958] who examined I 29 strains, mainly isolated from human faeces, and concluded (1957 b) that motile organisms constituted a special subgroup distinct from Streptococcus glycerinaceus ( $S$. faecalis), $S$. faecium and $S$. durans. He further subdivided the motile organisms into a yellow pigmented group and a non-pigmented group. (In the case of strains of the pigmented group studied in this present work, slight pigment formation was observed in colonies grown on horse blood agar at $30^{\circ}$ for several days.) Hugh (I959) studied six motile strains, including four of the ATCC strains used in this present work, and concluded that they were a variety of $S$. faecalis, without referring to the distinction between $S$. faecalis and $S$. faecium. He reported that the organisms fermented arabinose and not sorbitol, reactions generally characteristic of $S$. faecium.

In the present work several motile strains were found to produce acid when growing in the presence of sorbitol. The change in colour of the indicator was usually less marked than in the case of typical Streptococcus faecalis and possibly it would not be observed in slightly different reaction conditions. The results in Table 2 show that the motile strains differed in several respects from typical $S$. faecalis and showed a greater similarity to $S$. faecium in these tests.

Serology. Three of the motile strains had previously been described as Streptococcus faecium type 29 (Sharpe \& Fewins, 1960; Barnes 1964). The remaining motile strains were tested against available antisera to I 7 S. faecium types. Only one further strain gave a reaction (ATCC 13638 , type 38); antisera were prepared to confirm these results, and antiserum to strain NCTC 4725 was prepared in order to elucidate 
further the relationships between serotype and esterase pattern in this group of organisms.

In relating the serological studies of motile organisms to those of non-motile enterococci the nature of the antigens detected in motile bacteria by this typing technique should be considered. Elliott (1960) showed that type-specific antigens of three strains of Streptococcus faecalis and one of $S$. durans were located in the cell wall and were probably carbohydrate. The chemical nature of the carbohydrate type antigen of these and other strains of $S$. faecalis has been the subject of later publications (Bleiweis \& Krause, 1965; Willers \& Michel, 1966). Sharpe (1964) compared the serological type strains of $S$. faecalis from several workers and confirmed that the type antigen was derived from the cell wall. The inactivation of these antigens by periodate was taken as evidence of their carbohydrate nature. This also appeared to be true for the type antigens of many strains of $S$. faecium (Barnes, 1964), in most cases these antigens were destroyed by treatment with $0.01 \mathrm{M}$-potassium periodate. The antigens of motile streptococci studied by these techniques showed no evidence of inactivation by periodate, treatment of extracts with sodium periodate at a higher concentration and for a longer time than used by Sharpe (1964) or Barnes (1964) had very little effect on the subsequent precipitin reaction. Among the range of $S$. faecium strains studied by Barnes, several were reported to give type antigens resistant to periodate, these included strains of types 29 and 38 , two of the three 'serotypes' studied in the present work.

The location of the antigen extracted from motile enterococci in these experiments has not been determined. Preliminary results indicate that it occurs at the cell surface since whole cells were used for immunization and for absorption of antisera. It is not flagellar since removal of flagella before acid extraction of strains P I 4/6 and NCTC 4725 gave no detectable decrease in precipitin reaction. An aim of the present work was to relate the study of esterase patterns to the most widely used method of serotyping the enterococci; no study has been made of the $\mathrm{H}$ antigens. The work of Graudal ( $1957 a$ ) seems to indicate a surprising lack of variation in flagellar antigens of motile, enterococci. Using agglutination reactions to study 129 strains he reported a great number of serological O-types, but 128 strains constituted one H-type and I strain another H-type.

Esterases. The finding that motile strains show diverse patterns of esterase enzymes indicates that this technique may be a useful aid to characterization of these strains. The results with strains of type 38 illustrate the difference which may occur between motile and non-motile strains within the same serotype, the former (ATCC 13638) having strong esterase bands, the latter (strain P I 7/8) having a different, much fainter esterase pattern. Motile strains within the same serotype may show different esterase patterns ('serotype 4725 '); this contrasts with the results found for Streptococcus faecalis (Lund, 1965), where a similar esterase pattern was found in strains of $S$. faecalis and its varieties 'zymogenes' and 'liquefaciens', and in strains from five serotypes.

Protein patterns. The protein patterns, in contrast to those of the esterases, indicated some features which seem to be common to these motile strains. Despite the diverse esterase patterns observed it is possible that much of the enzyme protein of these organisms is very similar. The motile strain of serotype 38 showed a different protein pattern from the non-motile strain of this serotype. 
Relationship of motile strains to Streptococcus faecalis and S. faecium. The protein patterns indicate that these motile strains form a group distinct from $S$. faecalis and $S$. faecium. The esterase patterns show a distinction from $S$. faecalis, strains of which give esterase patterns different from those of any of the motile strains, and from S. faecium, strains of which show much fainter esterase bands.

The author is grateful to Dr E. M. Barnes, to Dr H. Graudal and to Dr R. Hugh for strains of motile organisms, to Dr E. M. Barnes and Dr S. D. Elliott for helpful discussions, to Professor W. I. B. Beveridge, School of Veterinary Medicine, Cambridge, for providing facilities for keeping rabbits, and to Miss E. Higgins for technical assistance.

\section{REFERENCES}

Auerbach, H. \& Felsenfeld, D. (1948). An unusual strain of Streptococcus isolated from subacute bacterial endocarditis. J. Bact. 56, 587.

Barnes, E. M. (1956). Methods for the isolation of faecal streptococci (Lancefield group D) from bacon factories. J. appl. Bact. 19, 193.

Barnes, E. M. (1964). Distribution and properties of serological types of Streptococcus faecium, Streptococcus durans and related strains. J. appl. Bact. 27, 46I.

Barnes, E. M., Ingram, M. \& Ingram, G. C. (1956). The distribution and significance of faecal streptococci in bacon factories. J. appl. Bact. 19 (2), 204.

Bleiweis, A. S. \& Krause, R. M. (1965). The cell walls of group D streptococci. I. The immunochemistry of the type I carbohydrate. J. exp. Med. x22, 237.

Cour tieu, A.-L., Le Tellier, H., Guillermet, F. N., Imbert, G. \& Longeray, C. (I964). Méningite purulente néonatale par entérocoque (variété mobile). Path. Biol., Paris 12, I235.

Cowan, S. T. \& SteeL, K. J. (1965). Manual for the Identification of Medical Bacteria. Cambridge University Press.

Deisel, R. H. (1964). The group D streptococci. Bact. Rev. 28, 330.

Deibel, R. H., LAKe, D. E. \& Niven, C. F. Jr. (1963). Physiology of the enterococci as related to their taxonomy. J. Bact. 86, 1275.

Ell.iotr, S. D. (1960). Type and group polysaccharides of group D streptococci. J. exp. Med. III, 621.

Fowler, R. C., Coble, D. W., Cranmer, N. C. \& Brown, T. McP. (I963). Starch gel electrophoresis of a fraction of certain of the pleuropneumonia-like group of organisms. J. Bact. 86, 1145 .

Graudal, H. (1952). Motile streptococci. Acta path. microbiol. scand. 31, 46.

Graudal, H. (1955). Undersøgelser over bevaegelige streptokokker. Københaven: Christtreus Bogtrykkeri.

Gratdal, H. (1957a). On the serology of motile streptococci. Acta path. microbiol. scand. 4r, 397.

Graudal, H. (1957b). The classification of motile streptococci within the enterococcus group. Acta path. microbiol. scand. 4I, 403.

Graudal, H. \& Birch-Anderson, A. (1958). Studies on the motility and flagellation of a motile streptococcus. Acta path. microbiol. scand. 43, 185.

HuGH, R. (1959). Motile streptococci isolated from the oropharyngeal region. Can. J. Microbiol. 5, 35I.

LANCEFIELD, R. C. (1933). A serological differentiation of human and other groups of haemolytic streptococci. J. exp. Med. 57, 571 .

Langston, C. W., Gutierrez, J. \& Bouma, C. (1960). Motile enterococci (Streptococcus faecium var. mobilis var. $N$ ) isolated from grass silage. $J$. Bact. 8o, 714 .

LEIFSON, E. (1951). Staining, shape and arrangement of bacterial flagella. J. Bact. 62, 377.

Liu, P., Lindberg, R. B. \& MASON, P. P. (1955). A motile streptococcus: electron micrographic observation. Kitasato Archs. exp. Med. 28, 63.

Lowry, O. H., Rosebrough, N. J., Farr, A. L. \& Randall, R. J. (I95I). Protein measurement with the Folin phenol reagent. J. biol. Chem. 193, 265. 
LuND, B. M. (1965). A comparison by the use of gel electrophoresis of soluble protein components and esterase enzymes of some group D streptococci. J. gen. Microbiol. 40, 4I3.

MAXted, W. R. \& Fraser, C. (1966). Sensitivity to acid of type antigens of Streptococcus faecalis. J. gen. Microbiol. 43, 145.

ØDEGAARD, A. \& GARDBORG, O. (1953). Investigations on a motile streptococcus isolated from blood culture. Acta path. microbiol. scand. 32, 275.

Pownall, M. (1935). A motile enterococcus. Br. J. exp. Path. 16, I 55.

de Saint Aubert, G., Dubouclard, G. C., Roumiantzeff, M. \& Vaugon, M. (1964). Contribution a l'étude de la mobilité de différentes souches de streptocoques $\mathrm{D}$ isolées de denrées alimentaires d'origine carnée. Annls Inst. Pasteur, Paris 106, 902.

SharPE, M. E. (1964). Serological types of Streptococcus faecalis and its varieties and their cell wall type antigens. J. gen. Microbiol. 36, I51.

Sharpe, M. E. \& FewINs, B. G. (1960). Serological typing of strains of Streptococcus faecium and unclassified group D streptococci isolated from canned hams and pig intestines. J. gen. Microbiol. 23, 621 .

Sharpe, M. E. \& Shattock, P. M. F. (1952). The serological typing of group D streptococci associated with outbreaks of neonatal diarrhoea. J. gen. Microbiol. 6, 150.

Sherman, J. M. (1937). The streptococci. Bact. Rev. I, I.

STOCKeR, B. A. D. \& CAMPBell, J. C. (1959). The effect of non-lethal deflagellation on bacterial motility and observations on flagellar regeneration. J. gen. Microbiol. 20, 670 .

Swift, H. F., Wilson, A. T. \& LANCEFIELD, R. C. (1943). Typing group A haemolytic streptococci by $\mathrm{M}$ precipitin reactions in capillary pipettes. J. exp. Med. $78,127$.

WhITTENBURY, R. (1963). The use of soft agar in the study of conditions affecting the utilization of fermentable substrates by lactic acid bacteria. J. gen. Microbiol. 32, 375 .

WiLleRs, J. M. N. \& MiCHEL, M. F. (1966). Immunochemistry of the type antigens of Streptococcus faecalis. J. gen. Microbiol. 43, 375.

\section{EXPLANATION OF PLATE}

(Studies of soluble components of disintegrates of motile group D streptococci by electrophoresis on polyacrylamide gel.)

Fig. I. Esterases of untyped motile streptococci (inserts $a-d$ ) and of strains reacting with antiserum to NCTC 4725 (inserts $e-j$ ). After electrophoresis the gel was incubated with $\alpha$-naphthyl acetate and Fast Blue BB to detect esterase enzymes. Photograph of gel shown diagrammatically in Fig. 5 (approximately actual size).

Fig. 2. Protein bands of untyped motile streptococci (inserts $a-d$ ) and of strains reacting with antiserum to NCTC 4725 (inserts $e-j$ ). After electrophoresis the gel was stained with naphthalene black to detect protein bands. Inserts contained the same series of extracts as in Fig. 5 and Pl. I, fig. I (approximately actual size). 


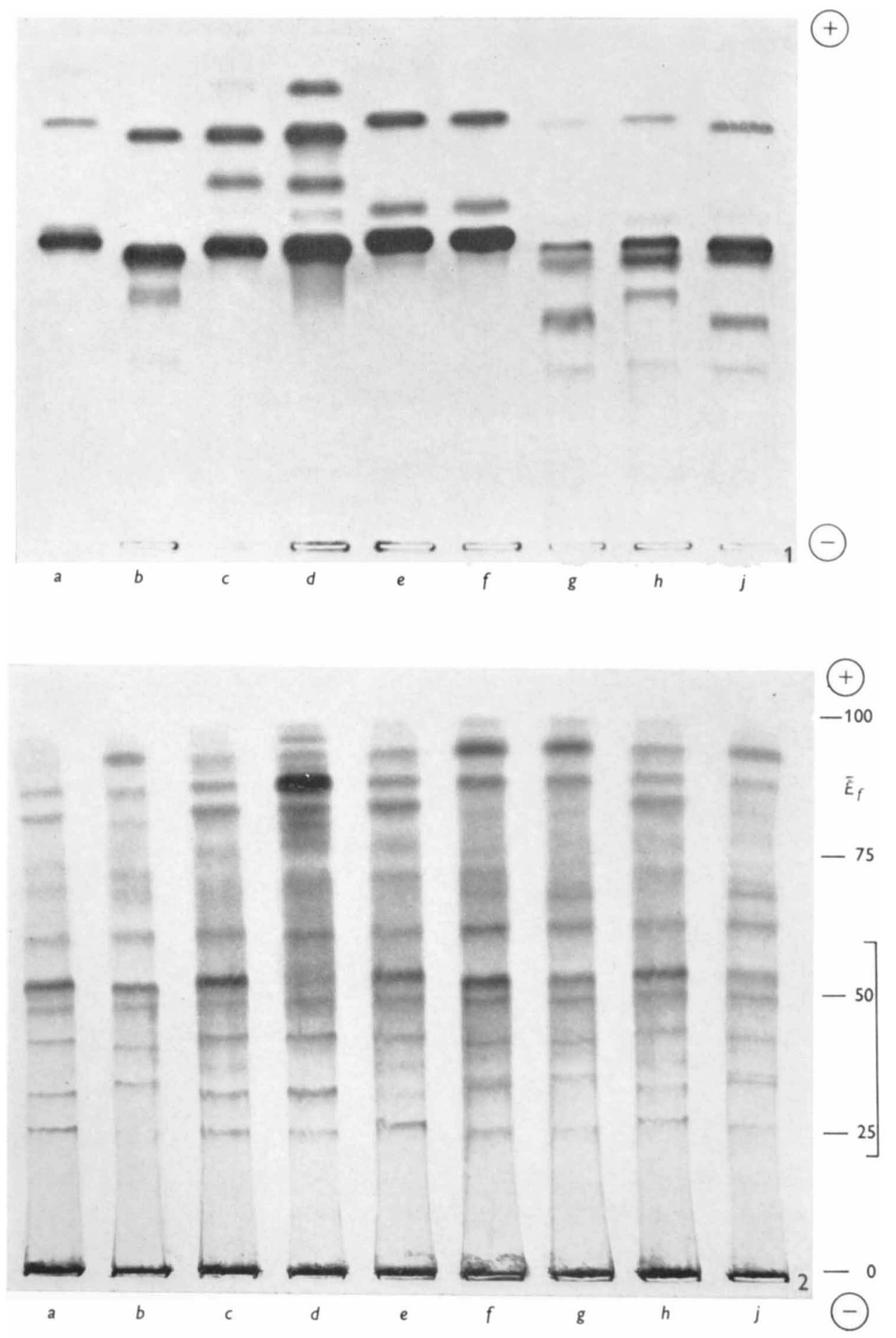

B. M. LUND 